\title{
Health, safety, and environmental risks from energy production: A year-long reality check
}

\author{
Curtis M. Oldenburg \\ Lawrence Berkeley National Laboratory \\ One Cyclotron Road \\ Berkeley, CA 94720 \\ CMOldenburg@lbl.gov, (510) 486-7419
}




\begin{abstract}
Large-scale carbon dioxide capture and storage (CCS) offers the benefit of reducing $\mathrm{CO}_{2}$ emissions and thereby mitigating climate change risk, but it will also bring its own health, safety, and environmental risks. Curtis M. Oldenburg, Editor-in-Chief, considers these risks in the context of the broader picture of energy production.

Over the last year, there have been major acute health, safety, and environmental (HSE) consequences related to accidents involving energy production from every major primary energy source. These are, in chronological order: (i) the Upper Big Branch (coal) Mine disaster, (ii) the Gulf of Mexico Macondo (oil) well blowout, (iii) the San Bruno (natural gas) pipeline leak and explosion, and (iv) the Fukushima (nuclear) reactor radioactivity releases.
\end{abstract}

Briefly, the Upper Big Branch Mine disaster occurred in West Virginia on April 5, 2010, when natural methane in the mine ignited, causing the deaths of 29 miners, the worst coal mine disaster in the USA since 1970.

Fifteen days later, the Macondo oil well in the Gulf of Mexico suffered a blowout, with a gas explosion and fire on the floating drilling platform that killed 11 people. The oil and gas continued to flow out of the well at the seafloor until July 15, 2010, spilling a total of approximately 5 million barrels of oil into the sea.

On September 9, 2010, a 30-inch (76-cm) buried, steel, natural gas pipeline in San Bruno, California, leaked gas and exploded in a residential neighborhood, killing 8 people in their homes and burning a total of 38 homes. Flames were up to $1000 \mathrm{ft}$ (300 m) high, and the initial explosion itself reportedly measured 1.1 on the Richter scale.

Finally, on March 11, 2011, a magnitude 9.0 earthquake off the coast of Japan's main island, Honshu, caused a tsunami that crippled the backup power and associated cooling systems for six reactor cores and their spent fuel storage tanks at the Fukushima nuclear power plant. At time of 
writing, workers trying to bring the crisis under control have been exposed to dangerous levels of radiation, and radioactive water and particulates have been released to the sea and atmosphere.

These four disasters, all of which occurred within the past 12 months, were not unprecedented; similar events differing only in detail have happened around the world before, and such events will occur again. Today, developed nations primarily use fossil fuels to create affordable energy for comforts such as lighting, heating and air-conditioning, refrigeration, transportation, education, and entertainment, as well as for powering manufacturing, which creates jobs and a wealth of material goods. In addition to the risks of the existing energy infrastructure that have become obvious through these recent disasters, there is also the ongoing risk of climate change that comes from the vast emissions of greenhouse gases, primarily $\mathrm{CO}_{2}$, from the burning of fossil fuels.

The implementation of $\mathrm{CO}_{2}$ capture and storage (CCS) will help mitigate $\mathrm{CO}_{2}$ emissions from fossil fuel energy, but it also carries with it HSE risks. In my personal interactions with the public and with students, the main concern voiced is whether $\mathrm{CO}_{2}$ could leak out of the deep reservoirs into which it is injected and rise up out of the ground, smothering people and animals at the ground surface. Another concern expressed is that $\mathrm{CO}_{2}$ pipelines could fail and cause similar gaseous plumes of $\mathrm{CO}_{2}$. The widespread concerns about $\mathrm{CO}_{2}$ leaking out over the ground surface may be inspired by events that have happened within natural systems in equatorial Africa, in Indonesia, and in Italy. ${ }^{1}$ Researchers have been investigating a wide variety of HSE risks of geologic $\mathrm{CO}_{2}$ storage for some time ${ }^{2}$ and have determined that wells are the main potential pathways for significant leakage from the deep subsurface. ${ }^{3}$ Below, I discuss the acute HSE risks of $\mathrm{CO}_{2}$ leakage through wells and from pipelines, and compare the behavior of failures in $\mathrm{CO}_{2}$ wells and pipelines with oil and gas analogues from which most of our experience derives.

\section{Risk terminology}

In the context of this discussion, risk (R) is calculated by multiplying the likelihood (L) of a given failure scenario by its consequences $(C)(R=L \times C)$. By this definition, high-probability 
events with small consequences may have the same level of risk as much lower probability events that have much greater consequences. Consequences can be divided into acute and chronic, where acute consequences are those that result in immediate or emergency situations involving the safety of individuals, and chronic consequences are those that may still be very serious but that occur over longer time frames. The Upper Big Branch Mine disaster and the San Bruno natural gas pipeline explosion were examples of acute consequences that caused multiple fatalities. The Macondo well blowout and Fukushima nuclear power plant meltdown disasters have both acute and chronic consequences.

\section{CCS geologic storage and transportation infrastructure}

The large-scale implementation of CCS at a level that will make a difference in mitigating fossilfuel $\mathrm{CO}_{2}$ emissions will involve a new infrastructure of wells and pipelines of the same approximate scale as that serving today's oil and gas industry. ${ }^{4}$ At this scale, thousands of deep $\mathrm{CO}_{2}$ injection wells may be in operation, and hundreds of thousands of miles of $\mathrm{CO}_{2}$ pipelines may be in use. Despite rigorous safety standards, high-quality materials, and monitoring and inspection protocols, failures of wells and pipelines are inevitable. Among the many causes of failures are human (operator) error, intentional disruptions and accidents, natural disasters such as earthquakes, and flaws in materials or control systems.

\section{$\mathrm{CO}_{2}$ storage infrastructure failure}

So what could the hypothetical geologic $\mathrm{CO}_{2}$ storage accidents of the future look like? We do not have to rely solely on speculation to address this question, since both $\mathrm{CO}_{2}$ well blowouts and $\mathrm{CO}_{2}$ pipeline accidents have happened in the past. ${ }^{5}$

\section{$\mathrm{CO}_{2}$ well blowout}


A blowout is defined as any uncontrolled upward flow of reservoir fluid in the well. In general, deep wells drilled for $\mathrm{CO}_{2}$ injection or monitoring must be carefully managed to avoid blowouts. The reason for this susceptibility to blowout is that like oil and gas, $\mathrm{CO}_{2}$ in the formation may be at hydrostatic or higher pressure, whereas the pressure contributed by the column of $\mathrm{CO}_{2}$ in the wellbore itself is less than hydrostatic because $\mathrm{CO}_{2}$ is not as dense as water. During drilling, heavy drilling fluids (so-called muds) are used to achieve whatever bottom-hole pressure is desired to control the upward flow of formation fluids. And blowout preventers (BOPs) are installed on finished wells to avoid blowouts. In general, new and improved technology have made blowouts of all kinds very rare today, ${ }^{6}$ although disasters still can occur for a variety of reasons, as evidenced by the Macondo well.

A CO 2 well blowout occurred in 1982, at Sheep Mountain, Colorado. ${ }^{7}$ Sheep Mountain is a large, natural $\mathrm{CO}_{2}$ reservoir that provides $\mathrm{CO}_{2}$ for enhanced oil recovery. Over the course of the 17 days of the blowout before engineers could kill the well, $\mathrm{CO}_{2}$ flowed freely out of the well and out of fissures in the ground. Grapefruit-sized chunks of dry ice, formed by Joule-Thomson cooling, were thrown high into the air by the pressure of the release. The energy of the discharge tended to disperse the $\mathrm{CO}_{2}$ gas, and there were no reports of hazardous accumulations of $\mathrm{CO}_{2}$ gas near the ground. Because $\mathrm{CO}_{2}$ is not flammable, there was also no hazard from fire or explosion.

This example at Sheep Mountain provides a close analogue of what a $\mathrm{CO}_{2}$ blowout from a geologic $\mathrm{CO}_{2}$ storage site might look like. In short, a $\mathrm{CO}_{2}$ blowout would be a rapid, uncontrolled release most likely with enough energy to dissipate the $\mathrm{CO}_{2}$ cloud above the ground surface, with no chance of causing a fire or explosion. Acute health and safety hazards would include loud noise from the rapidly discharging gas and possible local projectiles of dry ice. It would be possible (but not likely) for high concentrations of $\mathrm{CO}_{2}$ to accumulate in topographic depressions and present an inhalation hazard (e.g. during the sublimation of a dry-ice bank), but only under enclosed conditions with little or no wind. ${ }^{8}$ 


\section{$\mathrm{CO}_{2}$ pipeline leakage}

Rapid discharge of $\mathrm{CO}_{2}$ from an above-ground pipeline or one in the shallow subsurface would outwardly resemble a $\mathrm{CO}_{2}$ well blowout insofar as both involve rapid depressurization and high flow rates of $\mathrm{CO}_{2}$ with potential for dry ice to form. The main difference is that a pipeline has emergency shut-off valves located at intervals along its route, which means the flow would be stopped upon activation of the valves. Nevertheless, noise and blowing chunks of dry ice are a hazard as long as the leak occurs. As in the well blowout, the energy associated with the discharge tends to enhance dispersion of the leaking $\mathrm{CO}_{2} .{ }^{9}$ In contrast to a natural gas pipeline, there would be no hazard that the leaking $\mathrm{CO}_{2}$ would catch on fire or explode, because $\mathrm{CO}_{2}$ is not flammable - in fact it is commonly used as a fire suppressant.

\section{Closing thoughts}

As much effort as is spent trying to minimize HSE risk related to the world's existing energy infrastructure, there will always be the chance of failure. Large-scale CCS offers the benefit of reducing $\mathrm{CO}_{2}$ emissions and thereby mitigating climate change risk, but it will also bring its own HSE risk. The fact that $\mathrm{CO}_{2}$ is not flammable decreases the acute HSE risks associated with geologic $\mathrm{CO}_{2}$ storage relative to the analogous infrastructure for the oil and gas industry (i.e.

wells and pipelines). Furthermore, because $\mathrm{CO}_{2}$ is a gas at ambient conditions, it will tend to mix with the atmosphere and dissipate, and not pose a chronic HSE hazard, assuming the source of leakage is stopped.

Large-scale $\mathrm{CO}_{2}$ discharge by well blowouts and pipeline leakage are not the only HSE risks associated with CCS. Research is ongoing to evaluate consequences of $\mathrm{CO}_{2}$ and brine migrating into groundwater resources, and to evaluate the likelihood and consequence of $\mathrm{CO}_{2}$ injection causing induced seismicity, a well-known consequence of fluid injection. These research efforts need to be expanded and accelerated to fully evaluate the risks and benefits of large-scale CCS, including long-term risks. 
Arguably, the biggest long-term risk to global HSE is the vast climate change experiment we are at present carrying out through unmitigated emissions of greenhouse gases into the atmosphere from burning fossil fuels. Mitigating climate change risk through implementation of CCS entails some level of HSE risk, but recent experience points to the CCS risks being much less than the acute risks we assume today that are associated with fossil fuel and nuclear energy production.

\section{Acknowledgment}

This work was supported by the Assistant Secretary for Fossil Energy, Office of Sequestration, Hydrogen, and Clean Coal Fuels, through the National Energy Technology Laboratory, U.S. Department of Energy, under Contract No. DE-AC02-05CH11231.

\section{References}

1. Lewicki JL, Birkholzer JT and Tsang C-F. Natural and industrial analogues for leakage of $\mathrm{CO}_{2}$ from storage reservoirs: identification of features, events, and processes and lessons learned. Environ Geol 52:457-467 (2007).

2. Oldenburg CM, Migration mechanisms and potential impacts of $\mathrm{CO}_{2}$ leakage and seepage, in Carbon Capture and Sequestration Integrating Technology, Monitoring, and Regulation, ed by WilsonE and GerardD. Blackwell Publishing Ames, Iowa, pp 127-146 (2007).

3. Gasda SE, Nordbotten JM and Celia MA. Vertical equilibrium with sub-scale analytical methods for geological $\mathrm{CO}_{2}$ sequestration. Computational Geosciences 13:469-481 (2007).

4. Van Alphen K, Noothout PM, Hekkert MP and Turkenburg WC. Evaluating the development of carbon capture and storage technologies in the United States. Renew Sust Energ Rev 14:971986 (2010).

5. Duncan IJ, Nicot J-P and Choi J-W. Risk assessment for future $\mathrm{CO}_{2}$ sequestration projects based $\mathrm{CO}_{2}$ enhanced oil recovery in the U.S. 9th International Conference on Greenhouse Gas Control Technologies (GHGT-9), Washington, DC, November 16-20, 2008. GCCC Digital Publication Series \#08-03i. 
6. Jordan PD and Benson SM. Well blowout rates and consequences in California Oil and Gas District 4 from 1991 to 2005: implications for geological storage of carbon dioxide. Environ Geol 57:1103-1123 (2009).

7. Lynch RD, McBride EJ, Perkins TK and Wiley ME. Dynamic kill of an uncontrolled $\mathrm{CO}_{2}$ well. J Petrol Technol 37:1267-1275 (1985).

8. Mazzoldi A, Hill T and Colls JJ. $\mathrm{CO}_{2}$ transportation for carbon capture and storage: Sublimation of carbon dioxide from a dry ice bank. Int J Greenhouse Gas Control 2:210-218 (2008).

9. Mazzoldi A, Hill T and Colls J. Assessing the risk for $\mathrm{CO}_{2}$ transportation within CCS projects, CFD modeling. Int J Greenhouse Gas Control. In press (2011). 


\section{DISCLAIMER}

This document was prepared as an account of work sponsored by the United States Government. While this document is believed to contain correct information, neither the United States Government nor any agency thereof, nor The Regents of the University of California, nor any of their employees, makes any warranty, express or implied, or assumes any legal responsibility for the accuracy, completeness, or usefulness of any information, apparatus, product, or process disclosed, or represents that its use would not infringe privately owned rights. Reference herein to any specific commercial product, process, or service by its trade name, trademark, manufacturer, or otherwise, does not necessarily constitute or imply its endorsement, recommendation, or favoring by the United States Government or any agency thereof, or The Regents of the University of California. The views and opinions of authors expressed herein do not necessarily state or reflect those of the United States Government or any agency thereof or The Regents of the University of California.

Ernest Orlando Lawrence Berkeley National Laboratory is an equal opportunity employer. 